Supporting Information

\title{
Near-Infrared Plasmon-Boosted Heat/Oxygen Enrichment for Reversing Rheumatoid Arthritis with Metal/Semiconductor Composites
}

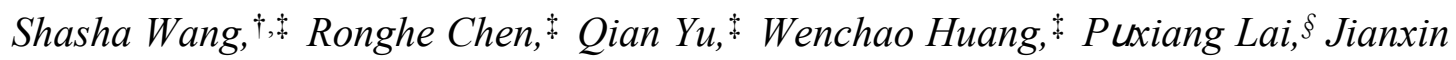
Tang, ${ }^{* \dagger}$ and Liming Nie*,:

${ }^{\dagger}$ Hunan Key Laboratory of Biomedical Nanomaterials and Devices, Hunan University of Technology, Zhuzhou 412007, P. R. China

*State Key Laboratory of Molecular Vaccinology and Molecular Diagnosis \& Center for Molecular Imaging and Translational Medicine, School of Public Health, Xiamen University, Xiamen 361102, P. R. China

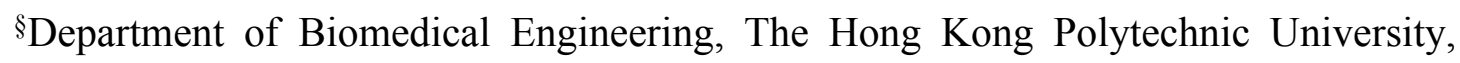
Hong Kong 999077, P. R. China

Corresponding Authors:

Jianxin Tang,*E-mail: jxtang0733@163.com.

Liming Nie, *E-mail: nielm@xmu.edu.cn. 


\section{EXPERIMENTAL SECTION}

Materials. Ultrapure water was obtained from a Milli-Q system. All chemicals were certified of analytical reagent grade and used without further purification. Gold (III) chloride trihydrate $\left(\mathrm{HAuCl}_{4},>98 \%\right)$, sodium borohydride $\left(\mathrm{NaBH}_{4}\right),{ }_{\mathrm{L}}$-ascorbic acid (AA), hydrochloric acid $(\mathrm{HCl})$, sodium hydroxide $(\mathrm{NaOH})$, hydrogen peroxide

$\left(\mathrm{H}_{2} \mathrm{O}_{2}\right), \quad$ ammonium $\quad$ hydroxide $\quad\left(\mathrm{NH}_{3} \cdot \mathrm{H}_{2} \mathrm{O}\right)$, 3-(4,5-Dimethylthiazol-2-yl)-2,5-diphenyltetrazolium bromide (MTT) were purchased from Sigma-Aldrich. Hexadecyl trimethylammonium bromide (CTAB, 99\%), silver nitrate $\left(\mathrm{AgNO}_{3}\right)$, cerium (III) nitrate hexahydrate $\left(\mathrm{Ce} \quad\left(\mathrm{NO}_{3}\right)_{3} \cdot 6 \mathrm{H}_{2} \mathrm{O}\right)$, ethylenediaminetetraacetic acid (EDTA), methoxy-PEG-thiol (mPEG-SH) were purchased from Aladdin.

Synthesis of $\mathrm{Au} @ \mathrm{CeO}_{2}$ Nanoparticles. Au nanorods were synthesized by the silver ion-assisted seed-mediated method with some modifications of the previous report. ${ }^{1-3}$ Primarily, $10 \mathrm{~mL}$ of the as-grown AuNRs solution was centrifuged at 12000 rpm for $20 \mathrm{~min}$ and then redistributed into $8 \mathrm{~mL}$ of CTAB solution $(0.025 \mathrm{M})$. Then, $0.8 \mathrm{~mL}$ of EDTA-NH${ }_{3}$ solution and $0.08 \mathrm{~mL}$ of $\mathrm{Ce}\left(\mathrm{NO}_{3}\right)_{3}(0.1 \mathrm{M})$ were added to the dispersion. The resulting solution was shaken for $2 \mathrm{~min}$ and then placed it in a $90{ }^{\circ} \mathrm{C}$ oil bath for 5-6 h. The $\mathrm{CeO}_{2}$-coated AuNR product was centrifuged at $5500 \mathrm{rpm}$ for $30 \mathrm{~min}$. Finally, $10 \mathrm{~mL}$ of $\mathrm{mPEG}-\mathrm{SH}$ solution $(4 \mathrm{mM})$ was added into $8 \mathrm{~mL}$ of the as-prepared $\mathrm{Au} @ \mathrm{CeO}_{2} \mathrm{NPs}$ solution, followed by stirring for 2 h. $\mathrm{Au} @ \mathrm{CeO}_{2}-\mathrm{PEG}$ NPs were separated from the solution by centrifugation at $6000 \mathrm{rpm}$ for $20 \mathrm{~min}$.

Characterization. Size and morphology of the nanoparticles were analyzed using a 
high-resolution transmission electron microscope (HRTEM, JEM-1400) operated at $200 \mathrm{kV}$. SEM imaging was determined on a FEI Quantum 400F microscope at an acceleration voltage of $20 \mathrm{kV}$. UV-vis-NIR absorption spectra were recorded using a spectrophotometer (UV-1750) (Shimadzu, Kyoto, Japan). The hydrodynamic diameter was measured by a Zetasizer Nano-ZS (Malvern Instruments). The powder XRD patterns were acquired on an AXS D8 advance (Bruker, Germany). Metal ion concentration analyses were carried out on an inductively coupled plasma-mass spectrometry (ICP-MS) (Thermo Fischer Scientific iCAP-QC). An optical fiber-coupled $808 \mathrm{~nm}$ laser (SBT Beijing Co., Ltd., China) was used to achieve photothermal increasing temperature.

Photothermal Effect of Nanoparticles. Firstly, the solutions of $200 \mu \mathrm{g} \mathrm{mL}^{-1}$ of AuNR, $\mathrm{CeO}_{2}$ and $\mathrm{Au} @ \mathrm{CeO}_{2}$ were irradiated under NIR laser $\left(808 \mathrm{~nm}, 1 \mathrm{~W} \mathrm{~cm}{ }^{-2}, \mathrm{SBT}\right.$ Beijing Co., Ltd., China) for $5 \mathrm{~min}$. Simultaneously, the real-time thermal images of the samples were recorded using a thermal camera and quantified using the monitoring software. Then, six concentration gradients of $\mathrm{Au} @ \mathrm{CeO}_{2}(0,12.5,25,50$, 100 and $200 \mu \mathrm{g} \mathrm{mL}^{-1}$ ) were irradiated by the $808 \mathrm{~nm}$ laser for $5 \mathrm{~min}$. Thermometry probe was served to record the temperature change every $50 \mathrm{~s}$.

$\mathrm{H}_{2} \mathrm{O}_{2}$ Decomposition Assay. A total of $100 \mu \mathrm{M}$ of $\mathrm{H}_{2} \mathrm{O}_{2}$ and $200 \mu \mathrm{g} \mathrm{mL}-1$ of AuNR, $\mathrm{CeO}_{2}$ and $\mathrm{Au} @ \mathrm{CeO}_{2}$ were respectively mixed into PBS in $15 \mathrm{~mL}$ centrifuge tubes at room temperature. Under the condition of with or without $808 \mathrm{~nm}$ laser irradiation, the $\mathrm{H}_{2} \mathrm{O}_{2}$ concentration was evaluated using a hydrogen peroxide assay kit by measuring the absorbance of the solution at $405 \mathrm{~nm}$ every $10 \mathrm{~min}$ to $1 \mathrm{~h}$. 
Oxygen Generation Assay. $200 \mu \mathrm{g} \mathrm{mL}^{-1}$ of $\mathrm{AuNR}, \mathrm{CeO}_{2}$ and $\mathrm{Au} @ \mathrm{CeO}_{2}$ was dispersed in PBS incorporating $100 \mu \mathrm{M}$ of $\mathrm{H}_{2} \mathrm{O}_{2}$ at room temperature. With or without $808 \mathrm{~nm}$ laser irradiation, oxygen generation levels were monitored until $1 \mathrm{~h}$ using a portable dissolved oxygen meter (JPBJ-608) every 10 min. Meanwhile, oxygen bubbles were observed in an Eppendorf tube. In addition, AuNR and $\mathrm{CeO}_{2}$ were mixed in PBS containing $100 \mu \mathrm{M}$ of $\mathrm{H}_{2} \mathrm{O}_{2}$, oxygen production capability of the mixed solution was measured over time by dissolved oxygen meter under $808 \mathrm{~nm}$ laser irradiation.

Cytotoxicity Assay. The in vitro cytotoxicity was investigated using a standard MTT assay. The RAW 264.7 cells were seeded into 96-well plates and cultured for 24 h. Then, the $\mathrm{Au} @ \mathrm{CeO}_{2}$ solutions with different concentrations $(0,12.5,25,50,100$ and $200 \mu \mathrm{g} \mathrm{mL}^{-1}$ ) were added to the plates and cocultured at $37^{\circ} \mathrm{C}$ for $24 \mathrm{~h}$. After that, $10 \%$ MTT solution was added and incubated at $37{ }^{\circ} \mathrm{C}$ for $4 \mathrm{~h}$. Finally, the MTT solution was removed and $200 \mu \mathrm{L}$ of DMSO was added to each well to dissolve the action products for $20 \mathrm{~min}$. The OD values were analyzed by measuring the absorbance at $490 \mathrm{~nm}$ using a microplate reader.

Enhancement of Photothermal Cytotoxicity In vitro. The LPS-induced macrophages RAW 264.7 cells at a density of $5 \times 10^{4}$ cells per $\mathrm{cm}^{2}$ were cultured in 96-well plates for $24 \mathrm{~h}$. Then the cells were cocultured with AuNR and $\mathrm{Au} @ \mathrm{CeO}_{2}$ at different concentrations $\left(0,12.5,25,50,100\right.$ and $\left.200 \mu \mathrm{g} \mathrm{mL}^{-1}\right)$ for another $24 \mathrm{~h}$, respectively. After that, the cells were washed twice with PBS to remove free nanoparticles and changed the medium to DMEM or PBS. Finally, the cells were 
irradiated with $808 \mathrm{~nm}$ laser $\left(1 \mathrm{~W} \mathrm{~cm}^{-2}\right)$ for $5 \mathrm{~min}$, and then incubated at $37{ }^{\circ} \mathrm{C}$ for 3 h. The photothermal induced cytotoxicity was determined by MTT assay.

The LPS-induced macrophages RAW 264.7 cells were seeded into 96-well plates and incubated at $37^{\circ} \mathrm{C}$ for $24 \mathrm{~h}$. Then the cells were randomly divided into six groups and cocultured with PBS, $200 \mu \mathrm{g} \mathrm{mL} \mathrm{L}^{-1}$ of AuNR, and $200 \mu \mathrm{g} \mathrm{mL} \mathrm{L}^{-1}$ of $\mathrm{Au} @ \mathrm{CeO}_{2}$ for $24 \mathrm{~h}$. After washing twice with PBS to remove excess nanoparticles, three groups of cells were irradiated with $808 \mathrm{~nm}$ laser $\left(1 \mathrm{~W} \mathrm{~cm}^{-2}\right)$ for $5 \mathrm{~min}$, and the other three groups did not need laser treatment, then incubated for $3 \mathrm{~h}$. To observe the cells enhanced therapeutic effect of $\mathrm{Au} @ \mathrm{CeO}_{2}$ intuitively, calcium fluorescein (AM) and PI were used to stain the living and dead cells and the cell images were observed by a laser confocal fluorescence microscope (LCFM, FV1200, Olympus, Tokyo, Japan).

Intracellular $\mathrm{H}_{2} \mathrm{O}_{2}$ Assay. Intracellular $\mathrm{H}_{2} \mathrm{O}_{2}$ assay (Sigma-Aldrich) was used to assess the intracellular $\mathrm{H}_{2} \mathrm{O}_{2}$ concentration. Firstly, a total of $100 \mu \mathrm{M}$ of $\mathrm{H}_{2} \mathrm{O}_{2}$ was added to the RAW 264.7 cells, which were pre-incubated with $200 \mu \mathrm{g} \mathrm{mL}^{-1}$ of $\mathrm{CeO}_{2}$ and $\mathrm{Au} @ \mathrm{CeO}_{2}$ for 24 h. Secondly, after 808 nm laser irradiation for $5 \mathrm{~min}$, the cells continued to be incubated for another $3 \mathrm{~h}$. Ultimately, the cell culture medium was replaced by $\mathrm{PBS}$, and the concentration of $\mathrm{H}_{2} \mathrm{O}_{2}$ in the cell was measured by fluorescence hydrogen peroxide detection kit $(\mathrm{ex} / \mathrm{em}=490 / 520 \mathrm{~nm})$.

Intracellular Inflammatory Cytokines Assay. The concentrations of TNF- $\alpha$, IL-6, and IL-1 $\beta$ in RAW 264.7 cells culture supernatants were determined by TNF- $\alpha$, IL-6, and IL-1 $\beta$ ELISA kits (Shanghai Neobioscience Technology Co., Ltd., China) according to the manufacturer's instructions. 
PAI Performance of Nanoparticles. To test the linearity of PA signals, six concentration gradients of the solutions of $\mathrm{AuNR}, \mathrm{CeO}_{2}$ and $\mathrm{Au} @ \mathrm{CeO}_{2}$ were employed for PA signals detection, respectively. In RA model mice, intraarticular injection of PBS, AuNR and $\mathrm{Au} @ \mathrm{CeO}_{2}$ at the same concentration $(200 \mu \mathrm{L}, 1 \mathrm{mg}$ $\left.\mathrm{kg}^{-1}\right)$. PA signals were utilized for monitoring the movement of nanoparticles in inflammatory joints at different time points. Total PAI datum of these samples were collected by a commercial Vevo LAZR system (FUJIFILM VisualSonics, Toronto, Canada), and the value of the PA signal was gained by partitioning the region of interest (ROI). 3D reconstruction PA images of the arthritis paws tracked the distribution of nanoparticles dynamically.

Collagen-Induced Arthritis Model. All animal experiments were carried out in compliance with the guidelines of the Institutional Animal Care and Use Committee of Xiamen University. Male 7- to 8- week-old Balb/c mice were used for establishing CIA model. Bovine type II collagen (CII) was dissolved in $0.05 \mathrm{M}$ glacial acetic acid at $4{ }^{\circ} \mathrm{C}$ overnight with total concentration of $2 \mathrm{mg} \mathrm{mL}^{-1}$. Then, the CII was fully emulsified with an equal volume of complete Freund's adjuvant (CFA). The right hind limbs of Balb/c male mice were sterilized with $75 \%$ alcohol, and the primary immunization was carried out by injecting $50 \mu \mathrm{L}$ CII emulsion into the middle skin of mouse foot about $3 \mathrm{~cm}$ away from the joint. Next, a booster injection of $25 \mu \mathrm{L}$ of CII emulsified in incomplete Freund's adjuvant (IFA) was given to mice at 21 days after the primary immunization.

PAI of Oxygen Levels in Ankle Joint. A commercial Vevo LAZR system 
(FUJIFILM VisualSonics, Toronto, Canada) was utilized for investigating vascular $\mathrm{sO}_{2}$ in the ankle joint cavity. $\mathrm{sO}_{2}$ around inflammatory joints in CIA mice model was determined before and after intra-articular injection of $200 \mu \mathrm{g} \mathrm{mL}-1$ of $\mathrm{Au} @ \mathrm{CeO}_{2}$ into the joints. After $808 \mathrm{~nm}$ laser irradiation, the differential optical absorption of deoxygenated and oxygenated hemoglobin at different wavelength of 750 and 850 $\mathrm{nm}$, respectively, was employed for measuring the levels of $\mathrm{sO}_{2}$ around inflammatory joints by a Vevo LAZR system.

Combined Therapy of Photothermal and Oxygen Production in vivo. CIA model mice were divided randomly into six groups and normal mice set as control group (n=6): (1) control, (2) PBS, (3) PBS + Laser (1 $\mathrm{W} \mathrm{cm}^{-2}$ for $\left.5 \mathrm{~min}\right)$, (4) AuNR, (5) $\mathrm{Au} @ \mathrm{CeO}_{2},(6) \mathrm{AuNR}+\operatorname{Laser}\left(1 \mathrm{~W} \mathrm{~cm}{ }^{-2}\right.$ for $\left.5 \mathrm{~min}\right)$, (7) $\mathrm{Au} @ \mathrm{CeO}_{2}+\operatorname{Laser}(1 \mathrm{~W}$ $\mathrm{cm}^{-2}$ for $\left.5 \mathrm{~min}\right)$. PBS, AuNR and $\mathrm{Au} @ \mathrm{CeO}_{2}$ were administered into synovial joints via intra-articular injection, respectively $\left(200 \mu \mathrm{L}, 1 \mathrm{mg} \mathrm{kg}^{-1}\right)$. Then the paws of the CIA rats were irradiated with an $808 \mathrm{~nm}$ laser at $1 \mathrm{~W} \mathrm{~cm}^{-2}$ for $5 \mathrm{~min}$ and the temperature change of the paw was carefully recorded by an IR thermal camera every $1 \mathrm{~min}$. Treatment was performed three times a week for a total of four weeks. Clinical index, ankle thickness and body weight were served as indexes to monitor the arthritis disease severity and progression. Clinical index of CIA mice was recorded by evaluating the evidence of erythema and swelling of each paw. The evaluated paws were graded individually from 0 to 4 based on the following scale: score $0=$ normal paw; score 1 = erythema and weak swelling of one toe; score $2=$ erythema and swelling on more than one toe; score $3=$ severe erythema and swelling of the entire 
paw; score 4 = complete erythema and swelling of the whole paw and ankle. Then the ankle thickness and the body weight of mice were gauged every four days via a digital caliper and an electronic scale, respectively.

Micro-CT Analysis. After four weeks of different treatments, the right hind limbs of CIA mice and normal mice were scanned on a 3D microcomputed tomography (micro-CT, SkyScan 1178, Bruker, Germany), respectively. Images of paws were gathered under the following scan parameters: tube voltage $=45 \mathrm{kV}$, tube current $=$ $550 \mu \mathrm{A}$, scanning resolution $=18 \mu \mathrm{m}$, rotation angle $=360^{\circ}$. Then the scanning images were reconstructed into 3D images using micro-CT software. 3D BMD (mg $\mathrm{cm}^{-3}$ ) and total bone volume (BV) of the arthritis joints were quantified to analyze the volumetric change of arthritis joints.

Histology Study. The mice were euthanized four weeks after each treatment and collected the right hind limbs for desquamation. Then all specimens were fixed in $10 \%$ formalin and decalcified with ethylenediaminetetraacetic acid decalcifying solution for four weeks. Joint tissues were embedded in paraffin, and microcosmically sliced into $5 \mu \mathrm{m}$ thick paraffin sections for H\&E staining or safranin-O staining. To analyze the expression of TNF- $\alpha$, IL-6, and IL- $1 \beta$ in the inflammatory tissue, ankle joint was stained with specific antibodies directed against TNF- $\alpha$, IL-6, and IL-1 $\beta$ (Abcam, UK). Peroxidase/dolichos bifows agglutinin (DAB) antibodies were served to the secondary antibody for chromagen development. All images were observed with a light microscope (CX31, Olympus).

qRT-PCR and Western Blot Analysis. Total RNA from the ankle joint of CIA 
mice or normal mice was extracted by a RNeasy Plus Mini Kit (Qiagen NV, Venlo, the Netherlands). NanoDrop spectrometer (ND-2000, Thermo Fisher Scientific, USA) was used for detecting the RNA concentration and purity. Then conversion of complementary DNA (cDNA) was performed using a reverse transcription kit (Thermo Fisher Scientific, USA) by following the manufacturer's instructions. Eventually, iQ SYBR Green Supermix (Bio-Rad) was added to cDNA to implement the qRT-PCR via the standard protocol.

Western blot analysis was used to evaluate the expression level of protein marker in inflammatory joints. The joint tissues were split by RIPA lysate containing protease inhibitor cocktail, then homogenated at $30000 \mathrm{rpm}$ for $10 \mathrm{~min}$ by an electric homogenizer. The supernatants were collected by centrifugation $13000 \mathrm{rpm}$ for 20 min at $4{ }^{\circ} \mathrm{C}$ for protein quantification and protein sample preparation, and the protein concentration was determined according to the instructions of BCA protein quantitative kit. After 20 min of electrophoresis at $90 \mathrm{~V}$, the proteins were transferred to a polyvinylidene fluoride (PVDF) membrane $(0.45 \mu \mathrm{m}$, Millipore, USA). The membranes were blocked with 5\% skim milk for $2 \mathrm{~h}$ to avoid non-specific binding. Then the membrane was incubated with primary antibodies against HIF- $1 \alpha$, TNF- $\alpha$, IL-6, and IL-1 $\beta$ (Abcam) for overnight at $4{ }^{\circ} \mathrm{C}$. The dilution ratio of anti-HIF-1 $\alpha$ antibody is $1: 200$, and that of anti-TNF- $\alpha$, anti-IL-6, anti-IL- $1 \beta$ and actin antibody is 1:1000. Membranes were washed with TBST on the second day and the next day, membranes were washed 3 times with TBS-T and incubated with secondary antibodies conjugated to horseradish peroxidase for $40 \mathrm{~min}$. Blotted membranes were 
visualized by a Gel Image System ver.4.00 (Tanon, China). Statistical Data Analysis: All statistical analyses were performed using GraphPad Prism v. Five (GraphPad Software Inc., CA, USA). Data were presented as mean \pm standard deviation. Significant differences were determined by one-way analysis of variance (ANOVA) and $\mathrm{P}<0.05$ was regarded as statistically significant. 
a

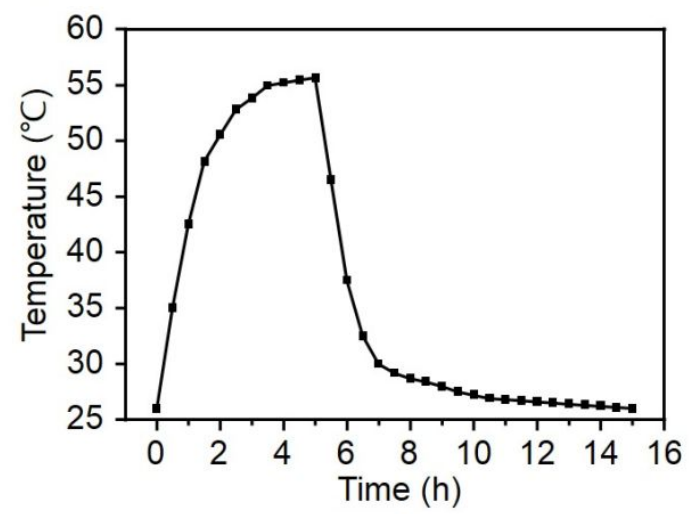

b

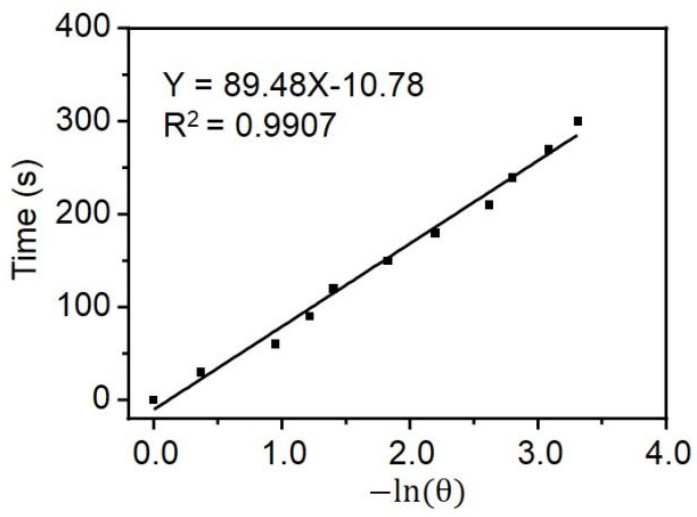

Figure S1. (a) Heating and cooling curves of $\mathrm{Au} @ \mathrm{CeO}_{2}$ solution $(100 \mu \mathrm{g} \mathrm{mL}-1)$ under $808 \mathrm{~nm}$ laser irradiation ( $\left.1 \mathrm{~W} \mathrm{~cm}^{-2}, 5 \mathrm{~min}\right)$. (b) The linear regression between cooling time versus the negative natural logarithm of the driving force temperature in (a). 


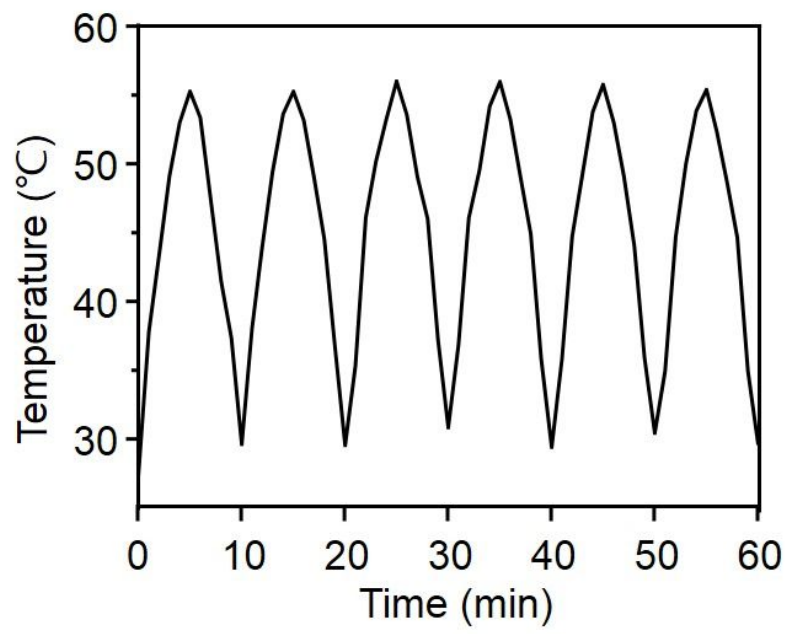

Figure S2. Photothermal heating and cooling curves of $\mathrm{Au} @ \mathrm{CeO}_{2}$ solution $(200 \mu \mathrm{g}$ $\mathrm{mL}^{-1}$ ) for five cycles. 

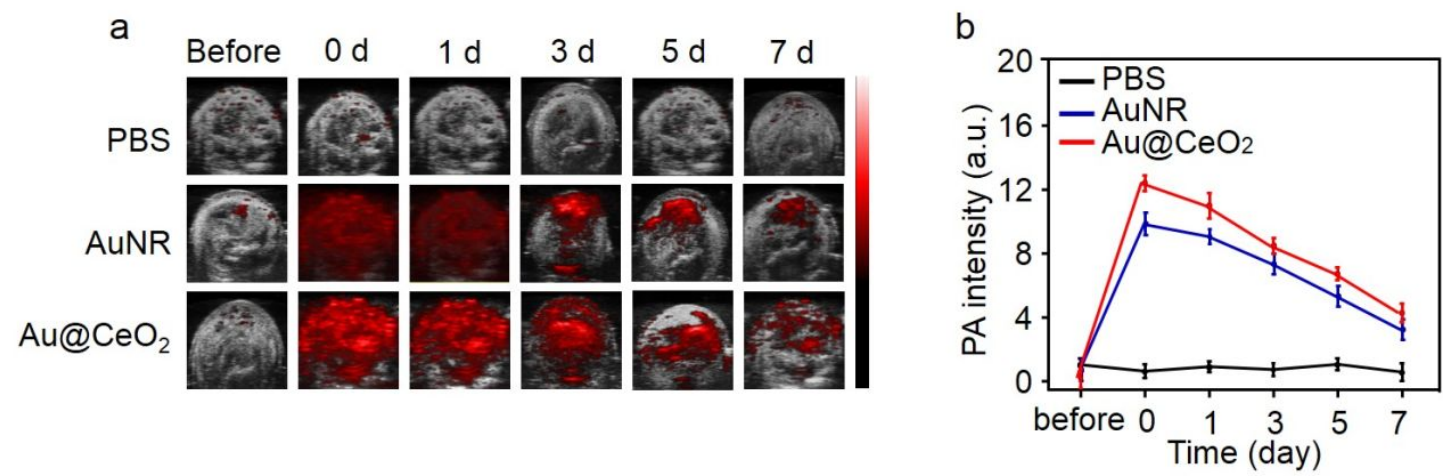

Figure S3. (a) PA images of RA mice before and after intra-articular injection administration of PBS, AuNR, and $\mathrm{Au} @ \mathrm{CeO}_{2}$ solutions $\left(50 \mu \mathrm{L}, 1.5 \mathrm{mg} \mathrm{kg}^{-1}\right)$ in one week. Scale bar is $2 \mathrm{~mm}$. (b) Corresponding PA signal intensities in (a). 

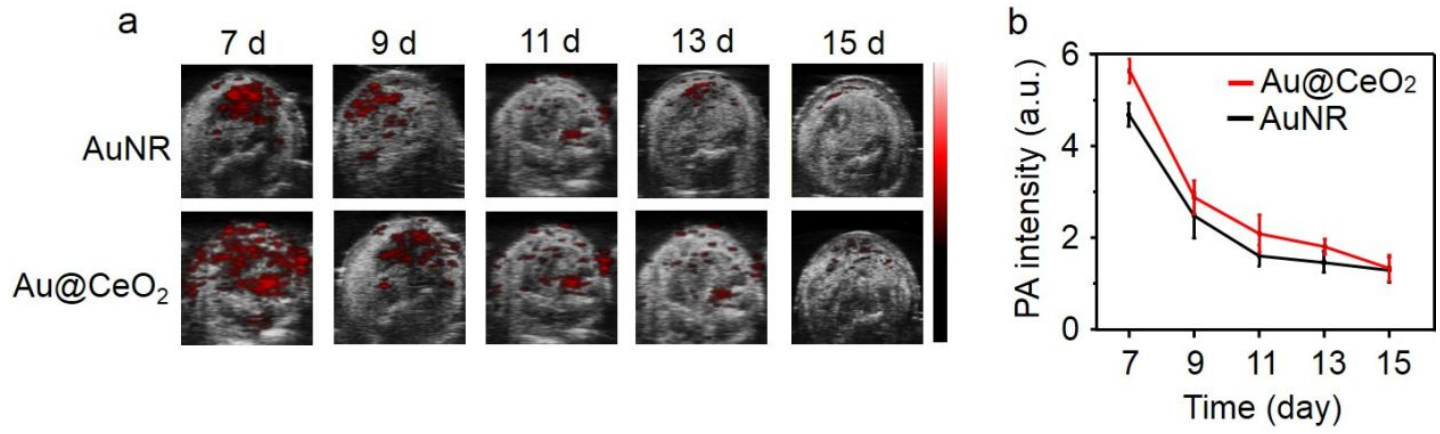

Figure S4. (a) PA images of AuNR and $\mathrm{Au} @ \mathrm{CeO}_{2}$ in articular cavity one week later.

Scale bar is $2 \mathrm{~mm}$. (b) Corresponding PA signal intensities in (a). 

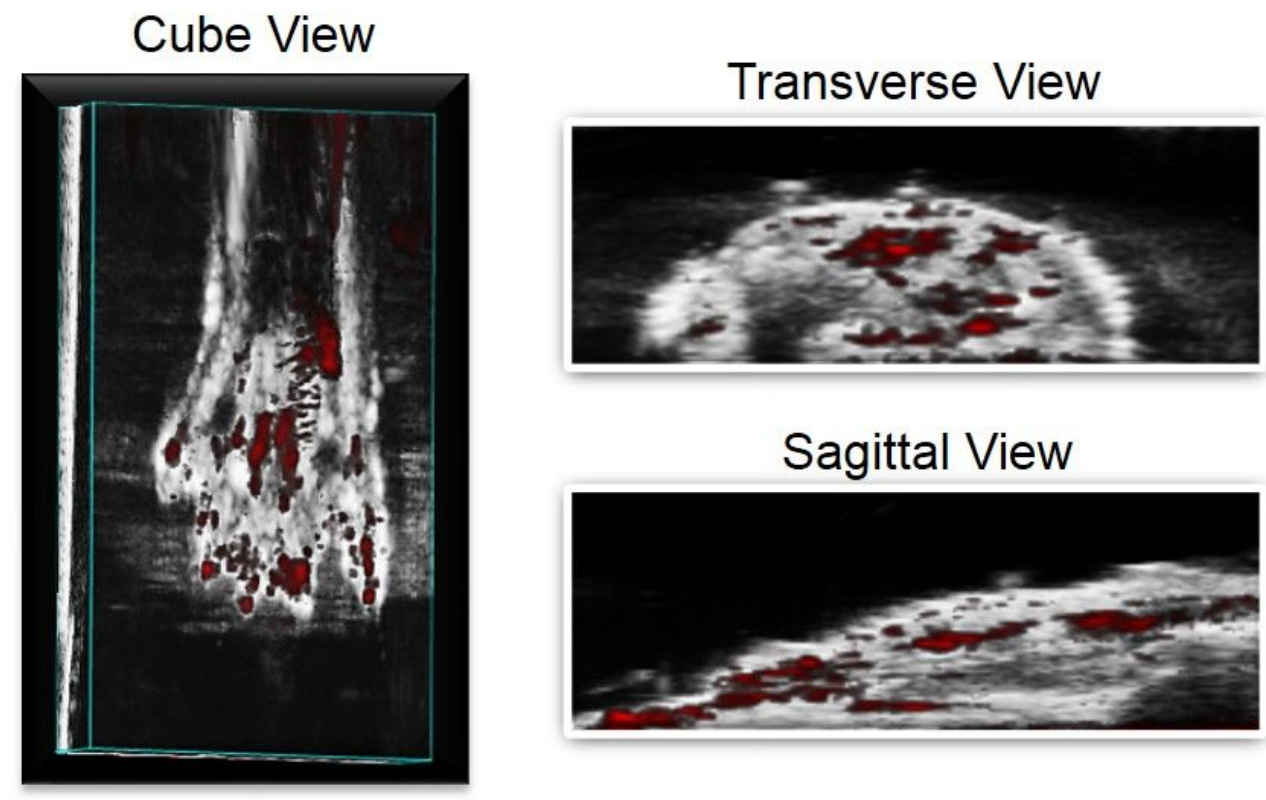

Figure S5. Representative cube, transverse and sagittal views of 3D reconstruction PA images of the arthritis paws for monitoring the distribution of $\mathrm{Au} @ \mathrm{CeO}_{2}$ on the 7 day of intra-articular injection administration. 

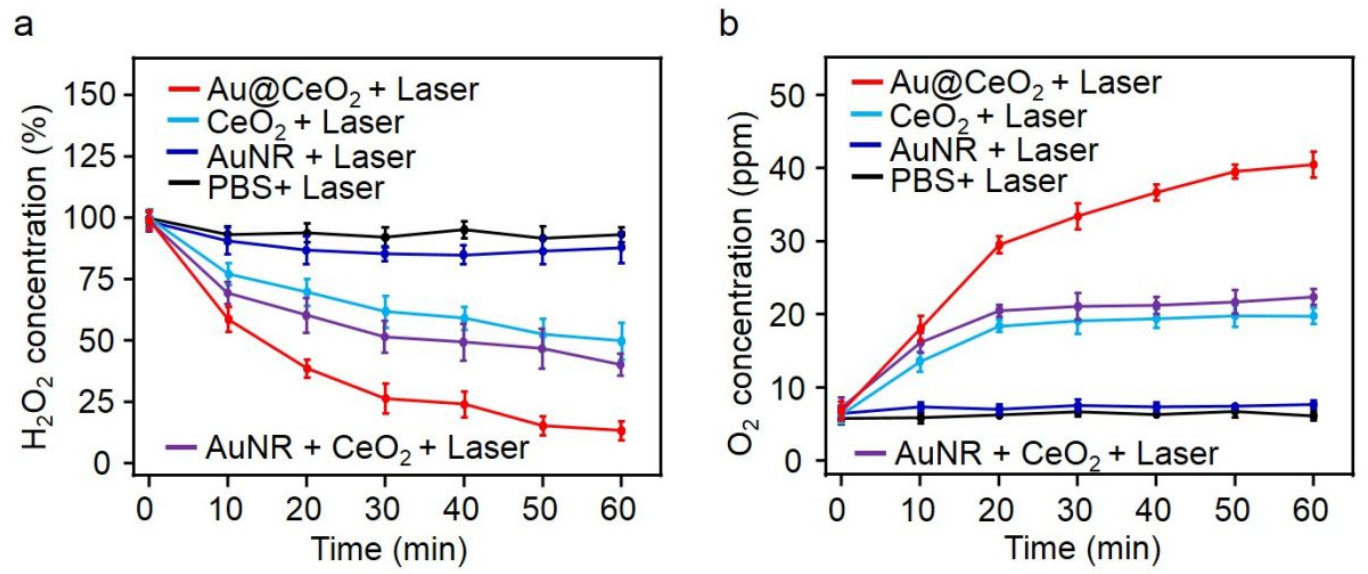

Figure S6. (a) Degradation curves of $\mathrm{H}_{2} \mathrm{O}_{2}$ with the mixture of AuNR and $\mathrm{CeO}_{2}$ compared with PBS, AuNR, $\mathrm{CeO}_{2}$, and $\mathrm{Au} @ \mathrm{CeO}_{2}$ with 808 nm laser irradiation at 1 W cm ${ }^{-2}$ in $1 \mathrm{~h}$. (b) Generation curves of $\mathrm{O}_{2}$ in $100 \mu \mathrm{M} \mathrm{H}_{2} \mathrm{O}_{2}$ solution with the mixture of AuNR and $\mathrm{CeO}_{2}$ compared with PBS, AuNR, $\mathrm{CeO}_{2}$, and $\mathrm{Au} @ \mathrm{CeO}_{2}$ with 808 nm laser irradiation at $1 \mathrm{~W} \mathrm{~cm}^{-2}$ in $1 \mathrm{~h}$. 


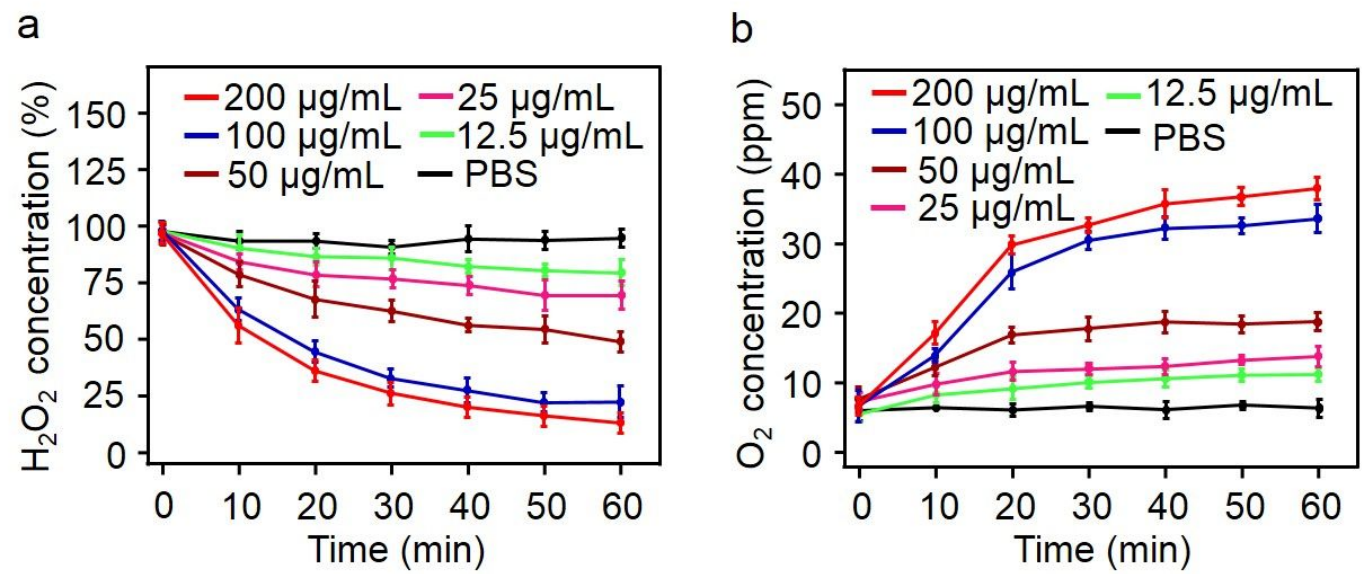

C

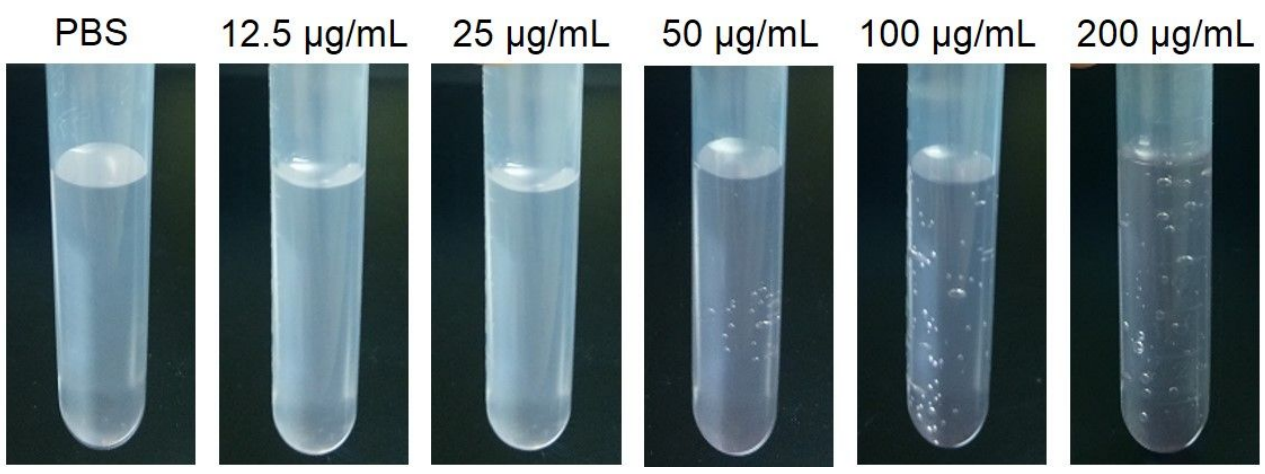

Figure S7. (a) Degradation curves of $\mathrm{H}_{2} \mathrm{O}_{2}$ at different concentrations of $\mathrm{Au} @ \mathrm{CeO}_{2}$ with $808 \mathrm{~nm}$ laser irradiation at $1 \mathrm{~W} \mathrm{~cm}^{-2}$ in $1 \mathrm{~h}$. (b) Generation curves of $\mathrm{O}_{2}$ at different concentrations of $\mathrm{Au} @ \mathrm{CeO}_{2}$. (c) Corresponding photographs of $\mathrm{O}_{2}$ generation. 


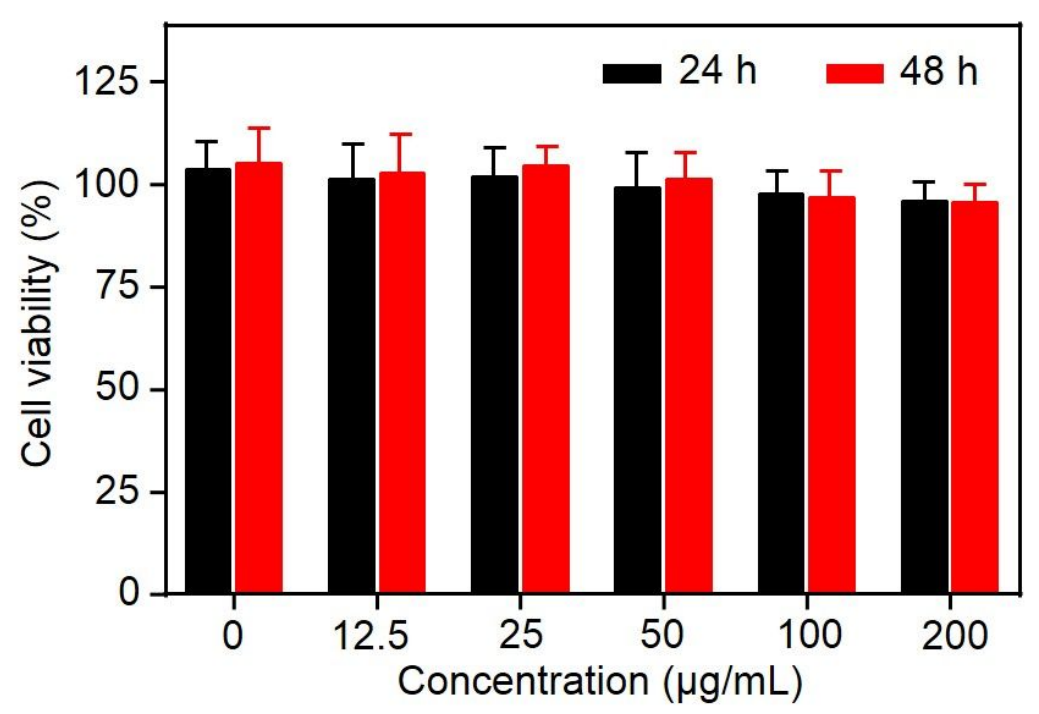

Figure S8. Viability of RAW 264.7 cells after incubation with different concentrations of $\mathrm{Au} @ \mathrm{CeO}_{2}$ for $24 \mathrm{~h}$ and 48 h. 


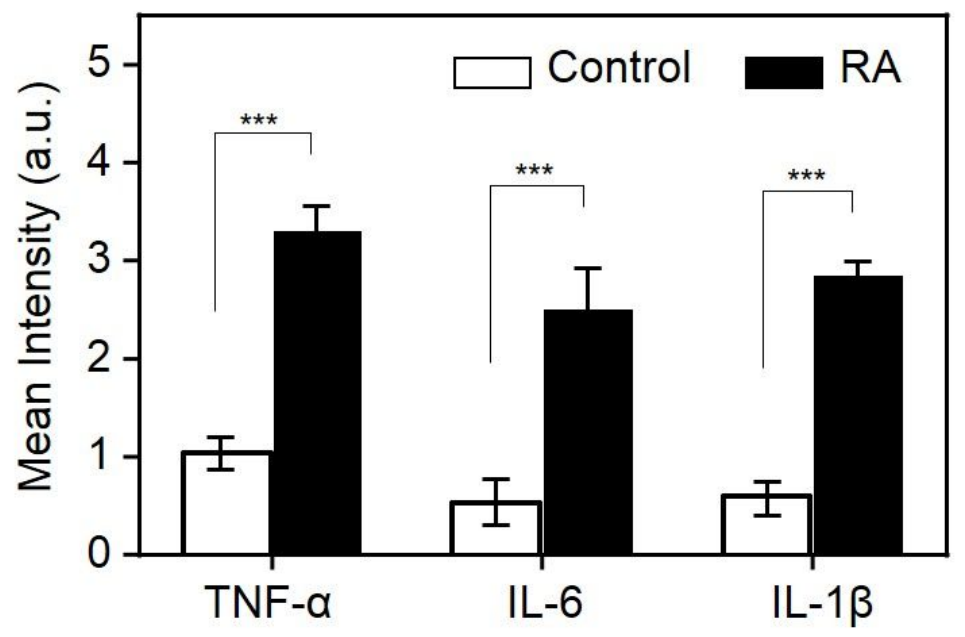

Figure S9. The levels of pro-inflammatory cytokines (TNF- $\alpha$, IL-6, and IL-1 $\beta$ ) in the LPS-induced RAW 264.7 cells and normal cells analyzed by ELISA kits. ${ }^{*} \mathrm{p}<0.05$, $* * \mathrm{p}<0.01, * * * \mathrm{p}<0.001$ 


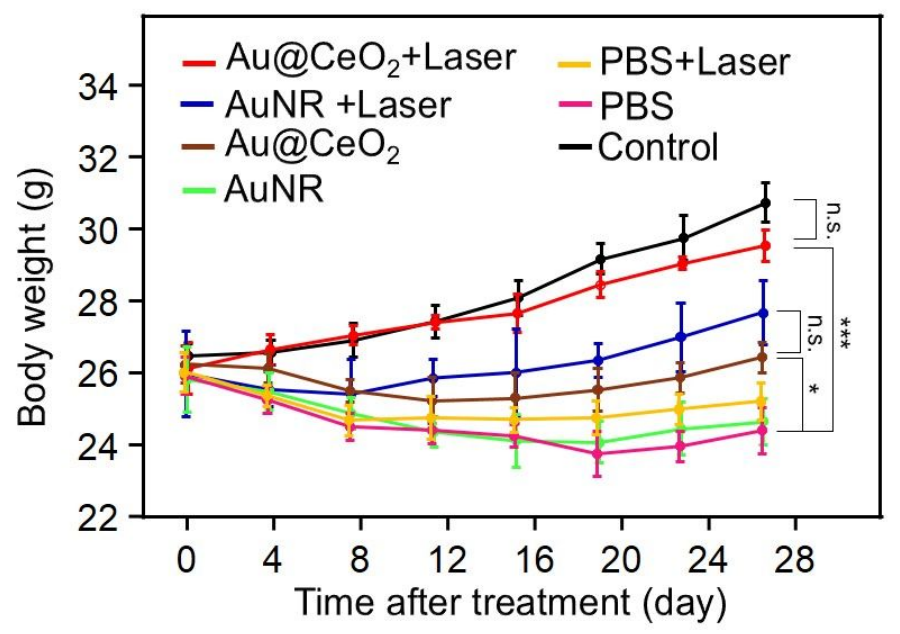

Figure S10. Weight change curves of CIA mice during treatment. Data presented as mean \pm SD. $* p<0.05, * * p<0.01, * * * p<0.001$, and n.s., no significance. 
a

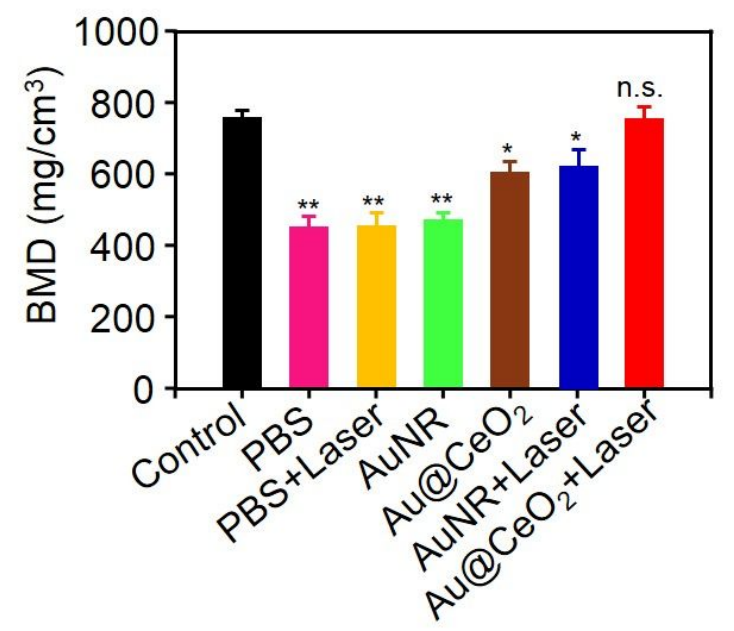

b

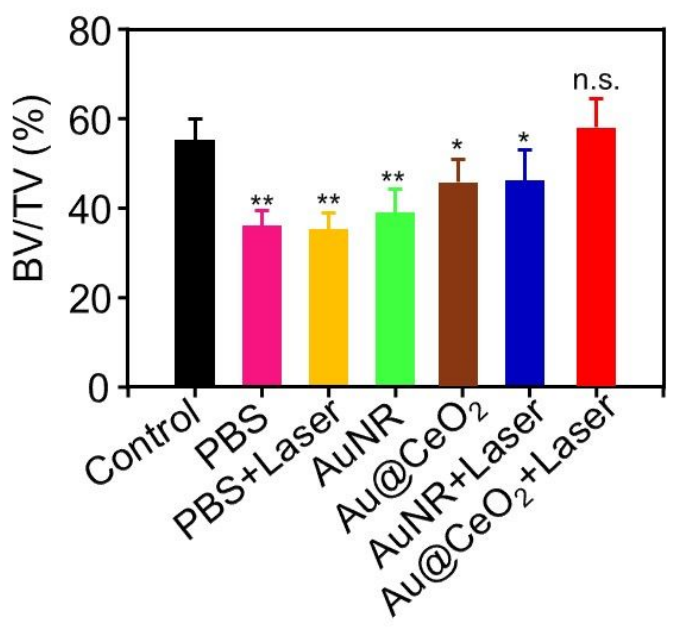

Figure S11. BMD (a) and BV/TV (b) of ankle joints after $28 \mathrm{~d}$ of different treatments. Data presented as mean $\pm \mathrm{SD}$. Asterisks $\left(^{*}\right)$ represents a significant difference compared with the control group. Data presented as mean \pm SD. ${ }^{*} \mathrm{p}<0.05$, $* * \mathrm{p}<0.01, * * * \mathrm{p}<0.001$, and n.s., no significance. 

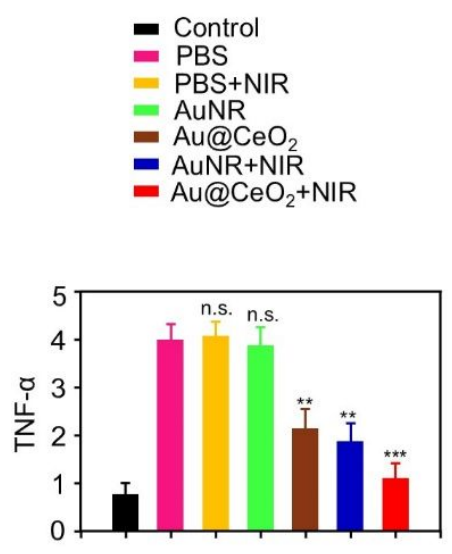
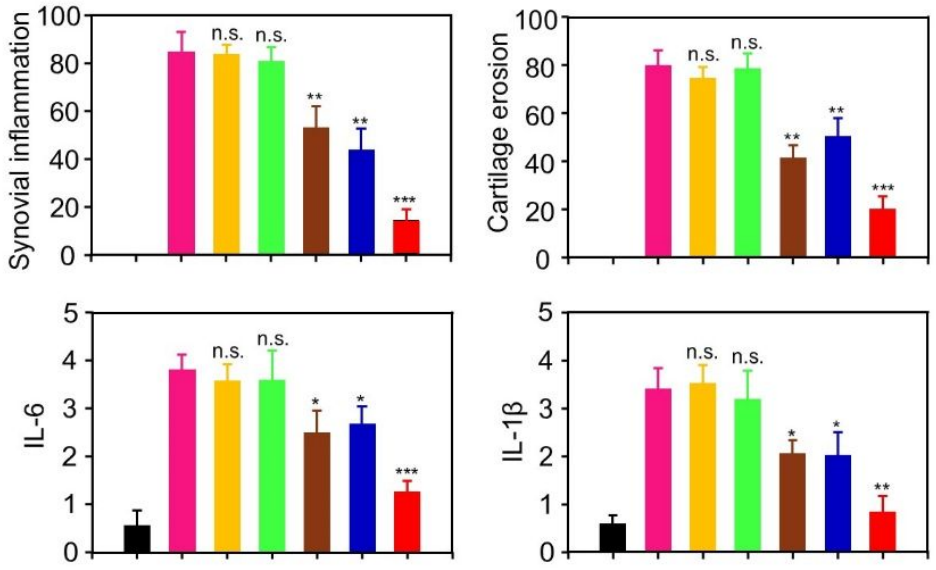

Figure S12. Quantitative analysis of histopathological assays (synovial inflammation and cartilage erosion) and immunohistochemical staining of TNF- $\alpha$, IL- 6 and IL-1 $\beta$ after $28 \mathrm{~d}$ of different treatments. Asterisks $(*)$ represent a significant difference compared with the mice treated with PBS. Data presented as mean \pm SD. ${ }^{*} p<0.05$, $* * \mathrm{p}<0.01, * * * \mathrm{p}<0.001$, and n.s., no significance.

\section{REFERENCES}

(1) Huang, X.; Neretina, S.; El-Sayed, M. A. Gold Nanorods: From Synthesis and Properties to Biological and Biomedical Applications. Adv. Mater. 2009, 21, 4880-4910.

(2) Nikoobakht, B.; El-Sayed, M. A. Preparation and Growth Mechanism of Gold 
Nanorods (NRs) Using Seed-Mediated Growth Method. Chem. Mater. 2003, 15, 1957-1962.

(3) Ni, W.; Kou, X.; Yang, Z.; Wang, J. Tailoring Longitudinal Surface Plasmon Wavelengths, Scattering and Absorption Cross Sections of Gold Nanorods. Acs Nano 2008, 2, 677-686. 